\title{
Efficient Application of the Radiance Enhancement Method for Detection of the Forest Fires Due to Combustion-Originated Reflectance
}

\author{
Rehan Siddiqui ${ }^{1,2,3^{*}}$, Rajinder K. Jagpal1,3, Sanjar M. Abrarov ${ }^{1,2,4}$, Brendan M. Quine ${ }^{2,3,4}$ \\ ${ }^{1}$ Epic College of Technology, Mississauga, Canada \\ ${ }^{2}$ Department of Earth and Space Science and Engineering, York University, Toronto, Canada \\ ${ }^{3}$ Department of Physics and Astronomy, York University, Toronto, Canada \\ ${ }^{4}$ Thoth Technology Inc., Algonquin Radio Observatory, Pembroke, Ontario, Canada \\ Email: *rehan@epiccollege.ca
}

How to cite this paper: Siddiqui, R., Jagpal, R.K., Abrarov, S.M. and Quine, B.M. (2021) Efficient Application of the Radiance Enhancement Method for Detection of the Forest Fires Due to Combustion-Originated Reflectance. Journal of Environmental Protection, 12, 717-733.

https://doi.org/10.4236/jep.2021.1210043

Received: September 10, 2021

Accepted: October 18, 2021

Published: October 21, 2021

Copyright $\odot 2021$ by author(s) and Scientific Research Publishing Inc. This work is licensed under the Creative Commons Attribution International License (CC BY 4.0).

http://creativecommons.org/licenses/by/4.0/

\begin{abstract}
The existing methods for detection of the cloud scenes are applied at relatively small spectral range within shortwave upwelling radiative wavelength flux. We have reported a new method for detection of the cloud scenes based on the Radiance Enhancement (RE). This method can be used to cover a significantly wider spectral range from $1100 \mathrm{~nm}$ to $1700 \mathrm{~nm}$ by using datasets from the space-orbiting micro-spectrometer Argus 1000. Due to high sunlight reflection of the smoke originated from the forest or field fires the proposed RE method can also be implemented for detection of combustion aerosols. This approach can be a promising technique for efficient detection and continuous monitor of the seasonal forest and field fires. To the best of our knowledge this is the first report showing how a cloud method can be generalized for efficient detection of the forest fires due to combustion-originated reflectance.
\end{abstract}

\section{Keywords}

Radiance Enhancement, Clouds, Forest Fire, Radiative Transfer Model, Line-By-Line Calculation, Micro-Spectrometer

\section{Introduction}

Increase of carbon dioxide gas appearing as a result of intense production of goods in industrial and agricultural sectors of economy is a main issue of the modern human society that causes uncontrollable rise of atmospheric tempera- 
ture due to devastating greenhouse effect. In particular, just in five decades the concentration of $\mathrm{CO}_{2}$ has been rapidly raised from $288 \mathrm{ppm}$ to more than 410 ppm in 2020 [1] [2] [3]. As a consequence, the global warming of the atmosphere affects the weather dynamics and causes a tremendous negative impact to the flora and fauna of the Earth [4].

The importance of clouds and their significant roles in sustaining the temperature balance on the Earth cannot be overestimated [5] [6] [7] [8]. However, a stable positive rate $2.05 \pm 0.03 \mathrm{ppm} /$ year of concentration of carbon dioxide greenhouse gas over the last decades increases the atmospheric temperature causing more intense water evaporation and formation of clouds [1]. Consequently, we observe more thunderstorms that drastically increase the chances for ignition of the forest fires due to lightning. As a result of global warming, the annual forest fire season in Canada has been extended from April to November [9]. Furthermore, a rapidly increasing population of Canada greatly intensifies tourism and hunting that ultimately causes forest fire ignitions due to absolutely uncontrollable conditions of camping. There were also reports that some arsonists can ignite forest fires purposely [10] [11].

Forest fires mostly burn down and destroy the pine trees in the North America. Pine trees grow extremely slow and, therefore, unlike many other species their recovery process may take many decades. The cold weather and clean environment are vital factors for their growth. However, increase of atmospheric temperature and anthropogenic pollutants significantly reduces chances for their survival. Consequently, the pine trees are gradually replaced by other species mainly by broadleaf trees and bushes. Pine trees are flammable and very vulnerable to heat. They are necessary sources of high quality wood that are used to build houses, furniture and electric poles to carry electricity. There are very limited resources that could replace pine trees and none of them are more cost-effective and better in quality. Therefore, losing these valuable pine forests may negatively affect the economy in the future [12].

The seasonal forest fires can last for many months and produce a large quantity of the smoke that endangers many animals by destroying their natural habitats [9] [12] [13]. Furthermore, according to the recent studies as a result of large areal coverage and prolonged exposure of the smokes containing hazardous aerosols, the forest fires can cause the various respiratory deceases including the lung cancer among local farmers in rural areas situated close to forests [14]. Therefore, detection and timely prevention of the forest fire spreads are highly needed.

Alongside with conventional methods based on MODIS and Google cloud database that provides precise and efficient probabilistic approach in determination of the multi-layered cloud masking [14] [15], the infra-red (IR) remote sensing is another approach for detection of clouds [8] [16] [17] [18]. In particular, in our recent publications we have described a new method for detection of cloud scenes based on the Radiance Enhancement (RE) method [17] [18]. Despite some drawbacks of the RE method such as lower resolution and difficulties to 
distinguish multi-layered clouds, its application, nevertheless, may be advantageous especially when remote sensing is provided from the space-orbiting IR micro-spectrometer like Argus 1000 [17] [18].

The ultra-light (about $0.25 \mathrm{~kg}$ only), small-size and inexpensive Argus 1000 instrument was launched into space in 2008 from India as a payload of the CanX2 nanosatellite [19] [20]. Being in space it provides the large-scale datasets as shown in Figure 1 that can be used to extract valuable information about atmospheric gas constituents like concentration of $\mathrm{CO}_{2}$ and other greenhouse gases by retrieving of the IR spectral radiance [20] [21] [22]. Inset in Figure 1 demonstrates a photo of the Argus 1000 micro-spectrometer.

Apart from determination of $\mathrm{CO}_{2}$ and other greenhouse gases, the IR radiance data collected by Argus instrument from space enable us to develop the RE method for efficient detection of the cloud scenes. Recently we suggested that a detection method of the cloud scenes can be generalized for detection of the forest and field fires [18] [23].

Figure 2 shows a map of Canada with forest fire locations depicted by the red spots [24]. In average a typical fire in a forest covers the range of a few squared kilometers only. However, its impact to the forest is much devastating. In particular, the forest fire causes the smoke that extends for tens and hundreds of squared kilometers increasing the temperature, spoiling air quality and preventing the sunlight locally for several months. Taking into consideration coverage areas of the spreading smokes, one can estimate from this map that about two thirds of the forest territories in Canada have been affected by forest fires during

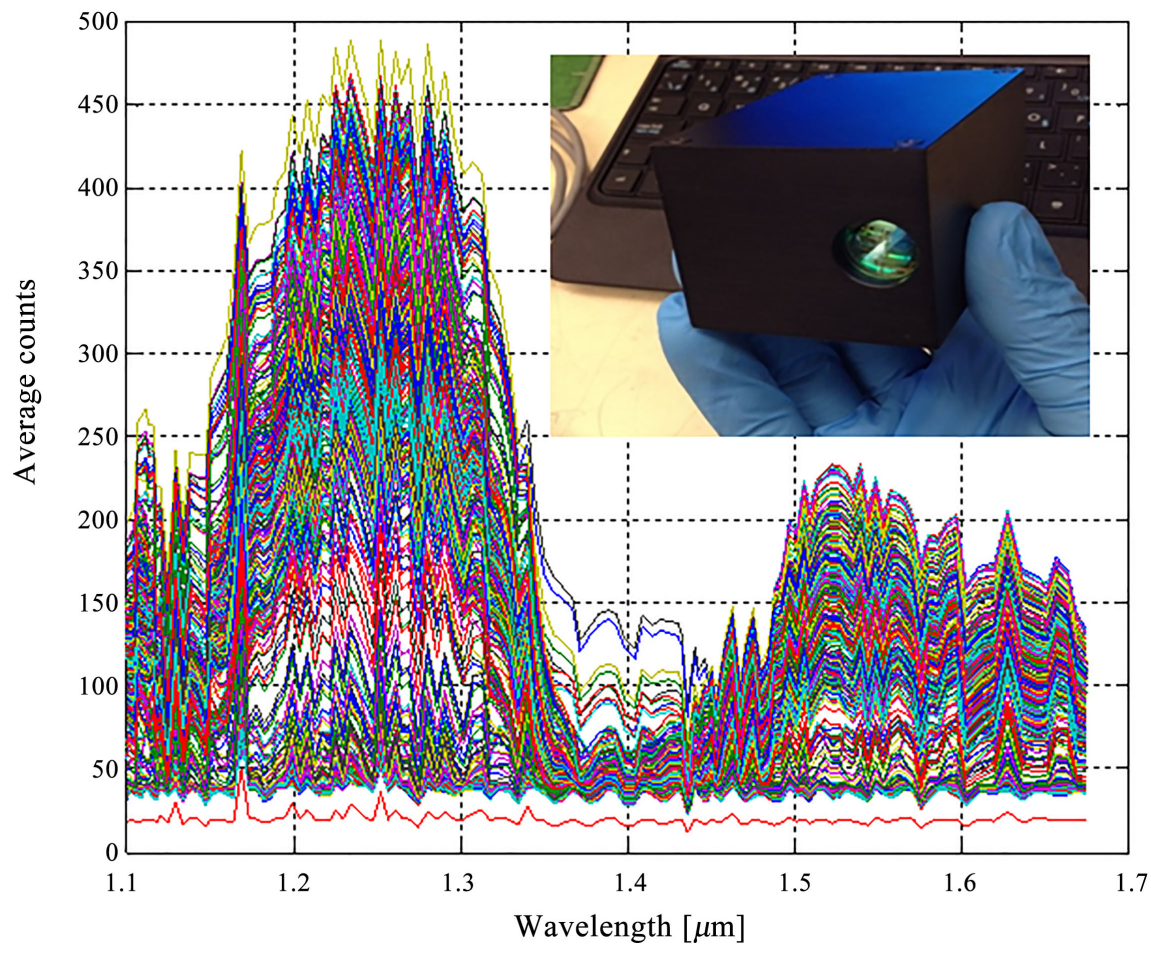

Figure 1. The space observation package of Argus 1000. Inset shows a photograph of the light and small-size Argus 1000 microspectrometer. 


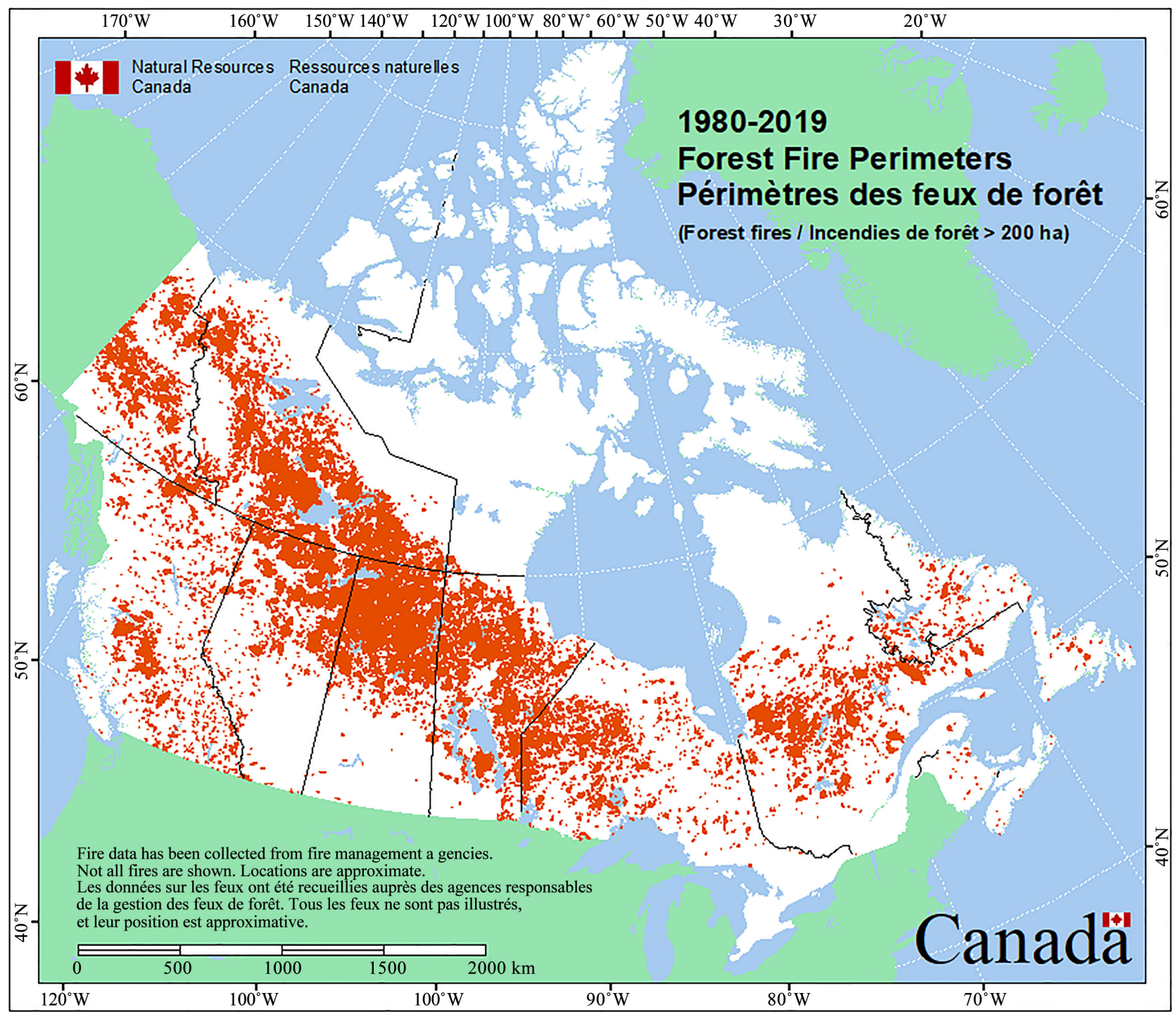

Figure 2. Map of Canada with forest fire locations during the period from 1980 to 2019 [24].

1980 to 2019 years [24]. The deficiency of the sunlight, pollution occurring due to smokes and an increased temperature of the environment can kill pine trees even in a larger quantity than the actual fire that burns them down. As a result, being unaffected directly by a fire these trees retain all material qualities including high density of wood and beam length. Consequently, these dead pine trees with high quality of wood are logged in a commercially large scale.

Conventional methods for forest fire detection include video-cameras, thermal imaging cameras, IR spectrometers to identify the spectral characteristics of smoke, light detection and ranging systems (LIDAR) and so on [25] [26] [27]. However, in contrast to the conventional methods, the RE technique has some advantages such as global coverage and continuous monitor due to periodic observation from the space-orbiting nanosatellite in the real time mode. Another important feature is that the RE method can cover a wide spectral wavelength range to detect enhancement of flux from the surface especially due to clouds 
[17] [18].

In this work we show how the RE technique can be used to detect efficiently the forest fires by using Argus 1000 space data. The main objectives of this study are to implement the RE to the line-by-line (LBL) forward radiative transfer model that accounts for wavelength dependency of surface reflectance with method of weighted sum and to show numerically a consistency between space observation and computed radiance spectra. Our method is based on a match between synthetic and observed radiance spectra that accounts for high surface reflectance appearing as a result of smokes produced by forest fires. A generalization of any water vapor cloud methods for detection of the forest fires has never been reported in scientific literature.

\section{Methodology}

The Radiance Enhancement methodology is based on least square match between space observation and synthetic datasets. In order to generate synthetic data we used LBL radiative transfer model GENSPECT [28]. This forward model computes the radiance for the nadir and limb observations for the greenhouse gases with all required parameters provided by the HITRAN molecular spectroscopic database [29]. Some supplementary MATLAB files are additionally developed to improve performance of the model. In particular, for computation of the absorption coefficients we applied a newly modified code for more rapid and accurate computation of the Voigt function based on a new single-domain interpolation technique [30] for which the highly accurate reference values can be generated by using any of three rapid algorithms described in our works [31] [32] or [33]. In contrast to the conventional algorithms [34] [35], in our implementation we interpolate the Voigt function in a single-domain itself in order to avoid unnecessary interpolation in computation of the absorption coefficients.

The model GENSPECT accounts for different variables that include concentrations of the greenhouse gases, deviation of the nadir angle, zenith angle of sun, and so on [28]. In the latest updates we developed some function files that also account for wavelength dependency of the reflectance due to different surface Albedo like clouds, pine-trees, vegetation and grass [36] [37] [38] [39]. The radiative transfer model is run in a nested loop by incrementing/decrementing values of the fitting variables until a best match is achieved. The RE methodology is based on the following formula [17] [18]

$$
\mathrm{RE}_{i}=\frac{1}{N} \sum_{j=1}^{N}\left\{\frac{\mathrm{OBS}_{i}[j]-\mathrm{SYN}_{i}[j]}{\operatorname{SYN}_{i}[j]}\right\},
$$

where $i$ is the index of wavelength sub-bands, $j$ is the index of grid-points and $N$ is the number of sub-bands that can be taken as 4 . This methodology shows the efficiency in determination of the cloud scenes. The corresponding Combined Radiance Enhancement (CRE) formula is given by [17] [18]

$$
\mathrm{CRE}=\sum_{j=1}^{N} \mathrm{RE}_{i},
$$


The RE and CRE values can be used to predict the cloud scenes. If the surface Albedo is relatively high, say above 0.6 , then the best match between observed and synthetic radiance signifies that the specific observation is likely due to thick cloud or any scattering particles such as ice pallets or aerosol. In this case we should expect that the RE and CRE values to be small by absolute values. Specifically, when CRE is relatively close to zero at high reflectance, we can expect higher chances for cloud scene for a specific location due to high surface Albedo. The CRE is predefined for the wavelength bands and accounts for concentration of the selected greenhouse gases [17] [18].

Although the RE method cannot distinct the cloud scenes with aerosols in from of solid particles and liquid droplets (including particulate matters $\mathrm{PM}_{2.5}$ [40]), it, nevertheless, can be advantageous in practical applications. If the weather forecast predicts no presence of clouds while the RE method shows their availability, then we can conclude that these type of reflectance could be due to aerosols like dust [41], industrial pollutants from big plants, hydroelectric stations or, more likely, combustion due to seasonal forest fires that typically produce a large amount of smokes. Consequently, as a result of high reflectance of the combustion-based aerosols, the RE method can also be used efficiently for detection of the forest fires.

Figure 3 shows flow-chart of the RE method for detection of the aerosol cloud due to forest fire that compares space observation and synthetic data. As we can see from this figure, in the intermediate stages the synthetic data is also divided into four sub-bands and passed to the slit function smoothing that simulates resolution of the Argus instrument. Once the RE computation is completed, the comparison of the space observation and synthetic data is performed and if there is a best match, then the corresponding observation data is chosen. The detailed description of the RE algorithmic implementation can be found in the work [17].

\section{Results and Discussion}

The LBL radiative transfer tool GENSPECT [28] generates synthetic spectral radiance for the greenhouse gases that can be used for comparison with space observation data. Figure 4 shows the synthetic spectral radiance for $\mathrm{CO}_{2}, \mathrm{H}_{2} \mathrm{O}, \mathrm{O}_{2}$ and $\mathrm{CH}_{4}$ gases computed at constant reflectance. The green shadow area is originally computed radiance while the red curve depicts the slit function smoothed radiance that simulates the limited resolution of the space instrument. The arrows in this figure indicate absorption band due to $\mathrm{O}_{2}$ near $1260 \mathrm{~nm}$, the wider band of absorptions due to water vapors from $1300 \mathrm{~nm}$ to $1480 \mathrm{~nm}$, two absorption bands near $1575 \mathrm{~nm}$ and $1600 \mathrm{~nm}$ are due to $\mathrm{CO}_{2}$ and one narrow absorption band near $1650 \mathrm{~nm}$ due to $\mathrm{CH}_{4}$ [20]. Each of these wavelength bands can be used in the RE method for the comparison with Argus observation data in order to detect cloud scenes and forest fires. Concentrations of $\mathrm{H}_{2} \mathrm{O}$ and $\mathrm{CO}_{2}$ bands are especially essential variables for matching of the synthetic model with space dataset from Argus 1000 micro-spectrometer. 


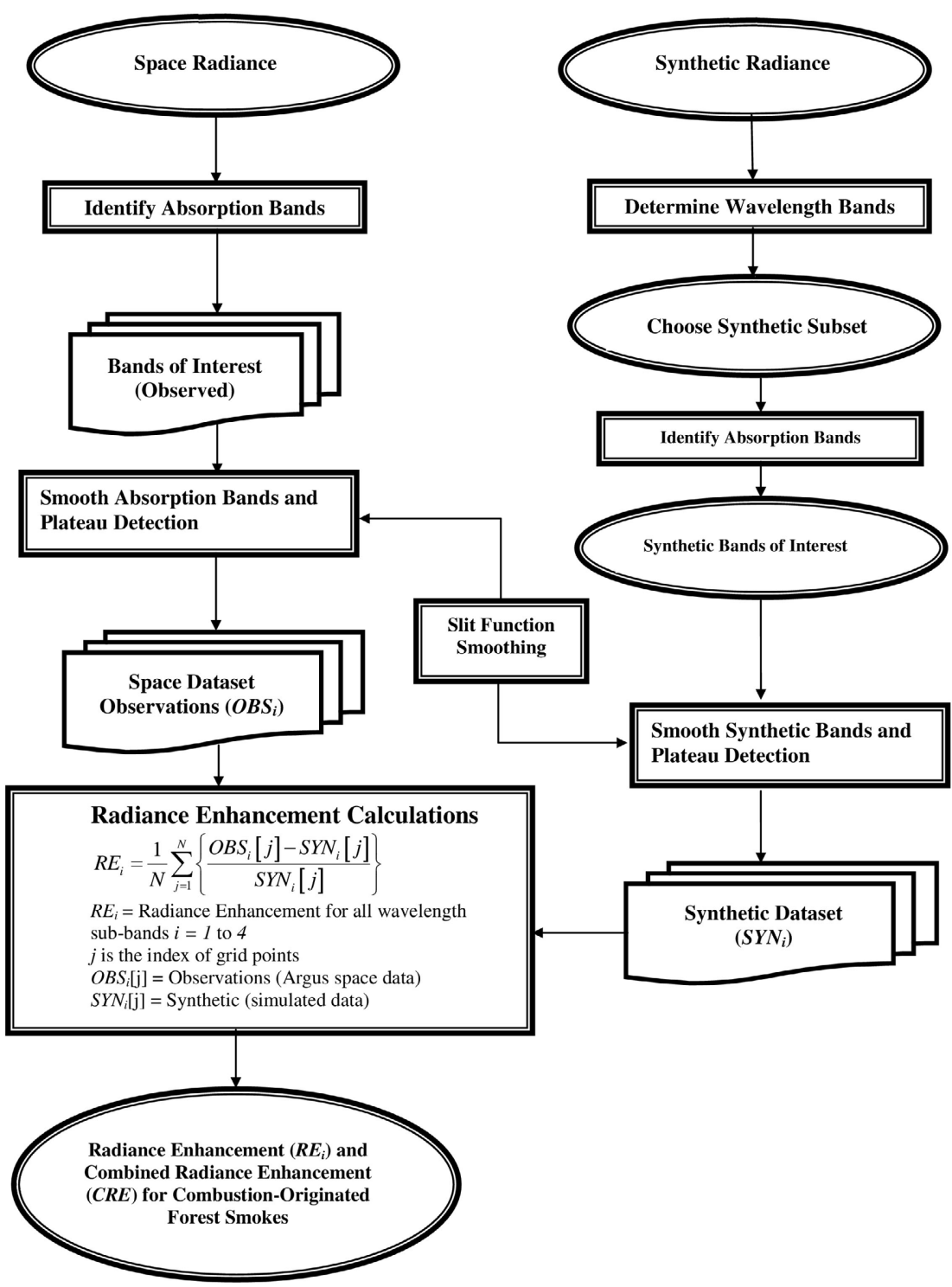

Figure 3. Flow-chart for computation of the RE method.

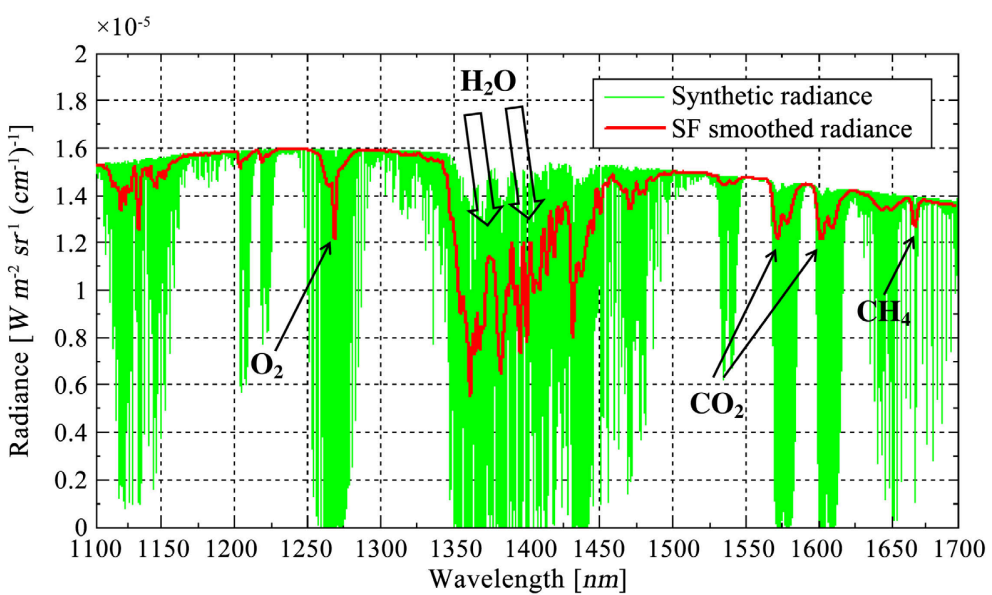

Figure 4. Synthetic radiance computed by radiative transfer model GENSPECT

[28] at a constant reflectance. 
The geolocation of the Argus instrument has been determined with help of Systems Tool Kit (STK) [42] [43] and [44] for location of the forest fires over Canada. The datasets from 2009 to 2015 for Argus instrument has been processed and analyzed for water vapor and combustion-based aerosol clouds. Figure 5 shows Argus 1000 path, observation numbers from 12 to 70 for week 11 and pass 69, over British Columbia, Canada. As we can see from Figure 5, the red spots indicating the actual forest fire locations intercept the trace of space orbiting IR remote sensor corresponding to observation packet numbers 12 to 52 .

Increase of atmospheric temperature gradually changes the canopy constituents of the forests; the burned and dead pine trees are not necessarily replaced by new generation of pine trees. Due to increasing atmospheric temperature, the chances for spreading of broadleaf trees and bushes are higher since for successful competition of young generation of the pine trees with other species a colder environment is highly preferable. Nowadays we can observe explicitly that after seasonal forest fires in the Algonquin National Park, Ontario, Canada, the pine trees are replaced by broadleaf trees, bushes and grasses changing the appearance and nature of the forest. Moreover, with development of the agricultural sector the more and larger territories of the forests are transformed to prairies, which are intensively used now by farmers for grazing cows, lambs, goats and horses. The density of trees in the forests is also declined due to increasing demand of most valuable wood of pine trees in the market and environmental pollutions.

Surface reflectance of forests is generally the wavelength dependent rather than a constant. Therefore, a more rigorous consideration requires that the reflectance has to include cumulative contribution of cloud, pine trees, vegetation (broadleaf trees and bushes) and grass. The visual analysis of the forest in British Columbia suggests that pine trees occupy 0.5 to 0.7 of the ground area, while remaining area is occupied by broadleaf trees, bushes and grasses. Figure 6 shows reflectance as a function of the wavelength for thick cloud, vegetation, pine trees and grass, which data can be obtained from [36] [37] [38] [39].

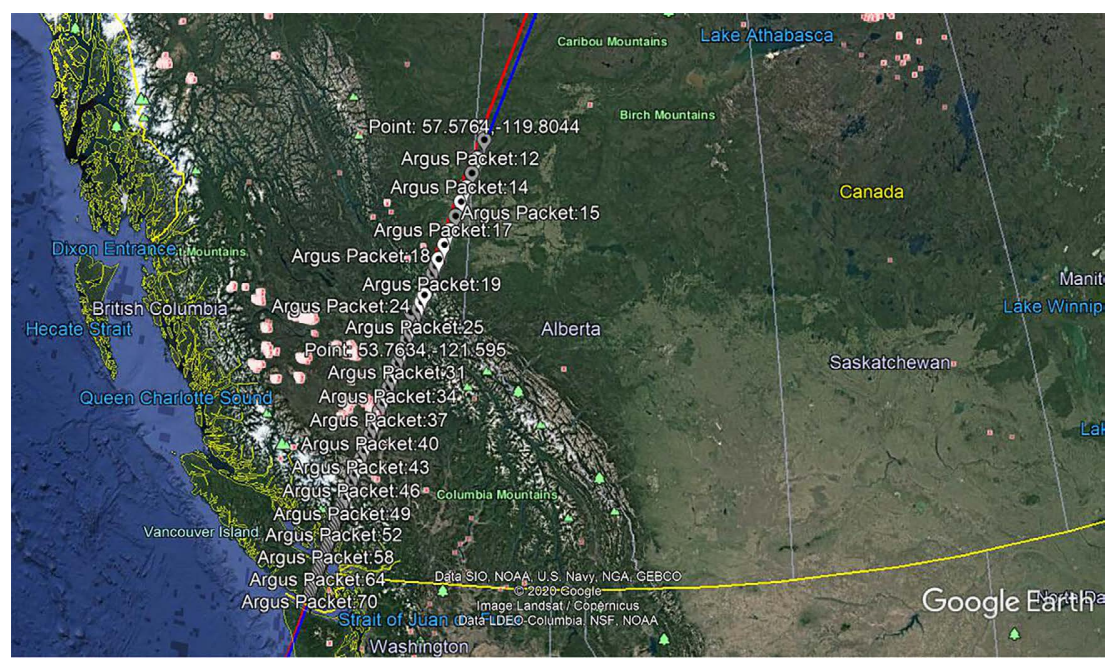

Figure 5. Geolocation of the Argus 1000 micro-spectrometer corresponding to week 11, pass 69 and observation numbers from 12 to 70, over British Columbia, Canada. 


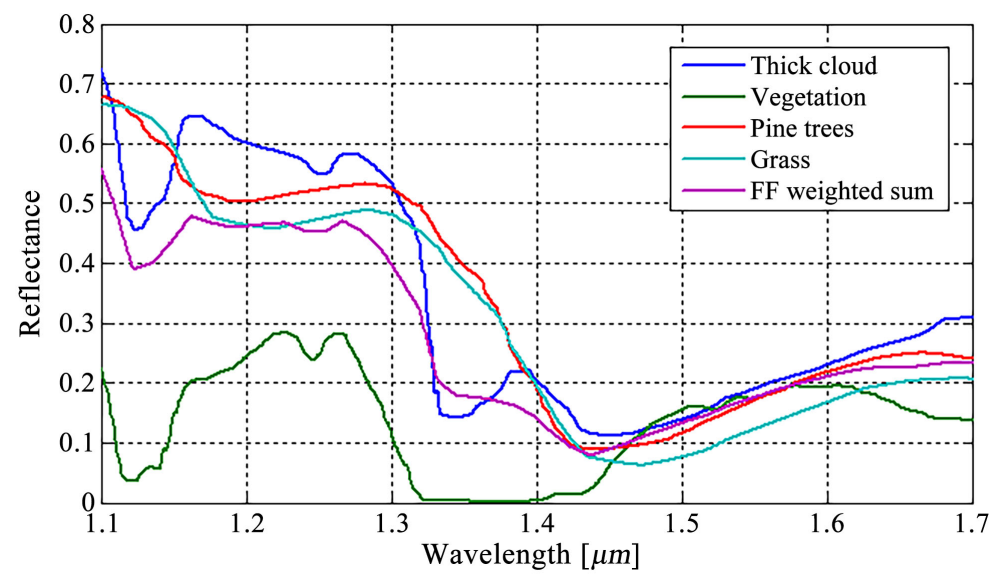

Figure 6. Reflectance dependencies for thick cloud, vegetation, pine trees, grass and their cumulative weighted sum.

The forests can occasionally share the land with turbid rivers and lakes. However, it is relatively rare when forest fires occur in the neighborhood of water. Therefore, we do not consider these events in our model. As an example, Figure 7 illustrates the evolution of the reflectance occurring due to contribution factor (CF) from the vegetation. In our model we consider cumulative reflectance from the surface due to thick cloud, pine trees, vegetation and grass. While the contribution factor from the vegetation changes from 0 to 1 (as shown in Figure 7), we imply that the relative ratios of the areal coverage corresponding to clouds, pine trees and grass remain same. Thus, the computation of cumulative reflectance was performed by weighted sum for all four types of surface reflectance.

Figure 8 shows the radiance computed at constant reflectance, thick cloud, vegetation, pine trees, grasses and by weighted sum due to forest fire (FF). As we can see from this figure, the wavelength dependency of the reflectance significantly changes the radiance. Particularly, the radiative transfer model GENSPECT [28] generates the graphs where the right portion above $1400 \mathrm{~nm}$ is suppressed. This suppression effect on the right part of the spectral region plays an important role in retrieval process of the space observable data. Despite this one can still observe the profound absorption bands near $1575 \mathrm{~nm}$ and $1600 \mathrm{~nm}$ due to carbon dioxide greenhouse gas.

Figure 9 shows the synthetic radiance (green shadow area) and slit function smoothed radiance (red curve) that accounts for the wavelength dependent radiance. Comparing Figure 4 and Figure 9 with each other we can observe significant changes in the radiance. However, it should be noted that despite the suppression on the right portion of the graphs above $1400 \mathrm{~nm}$, the two absorption bands of $\mathrm{CO}_{2}$ greenhouse gas near $1575 \mathrm{~nm}$ and $1600 \mathrm{~nm}$ still remain profound.

It has been found by experimental fitting that $\mathrm{CF}=0.3$ provides the best match between synthetic and space observable data. This can be seen from the Figure 10 showing the space observation and synthetic radiance spectra. It should be noted that at $1575 \mathrm{~nm}$ and $1600 \mathrm{~nm}$ we can observe a relatively good match 


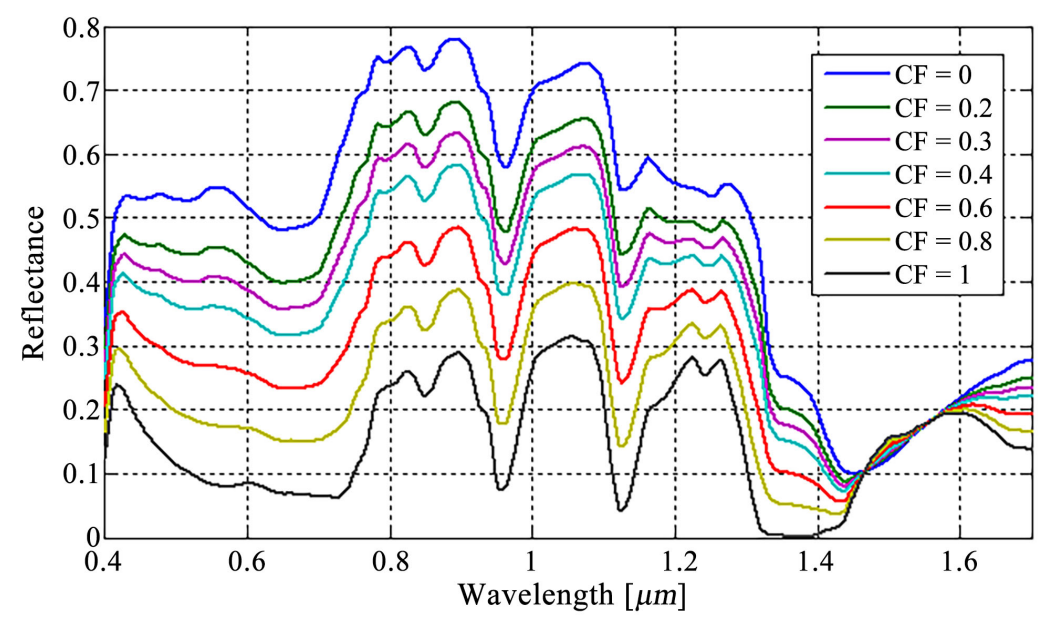

Figure 7. Reflectance dependencies for thick cloud, vegetation, pine trees, grass and their cumulative weighted sum.

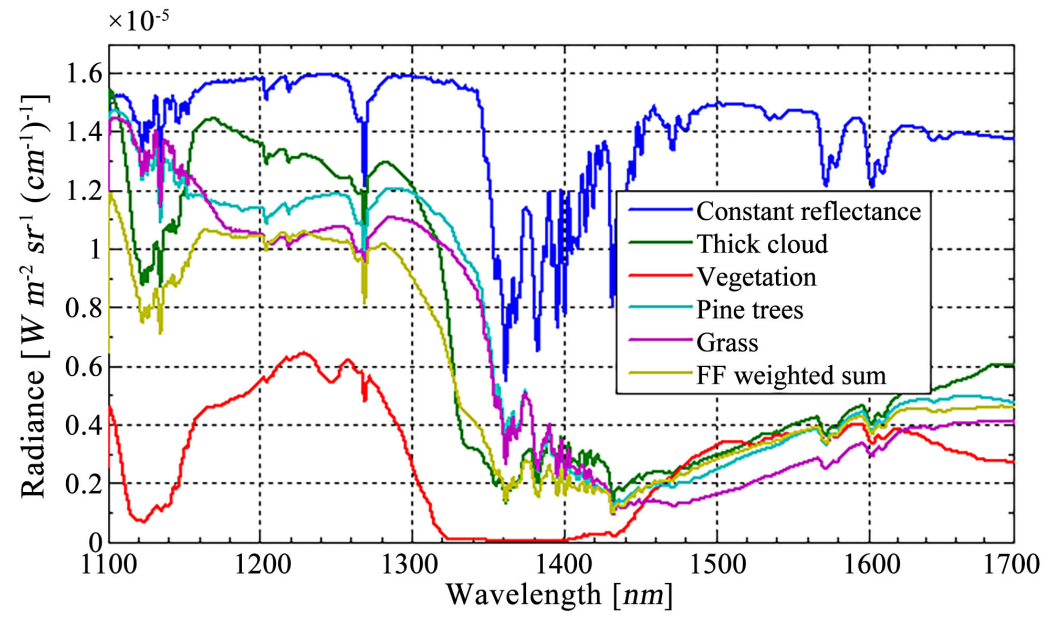

Figure 8. Synthetic radiance (all slit function smoothed) computed at different wavelength dependent reflectance.

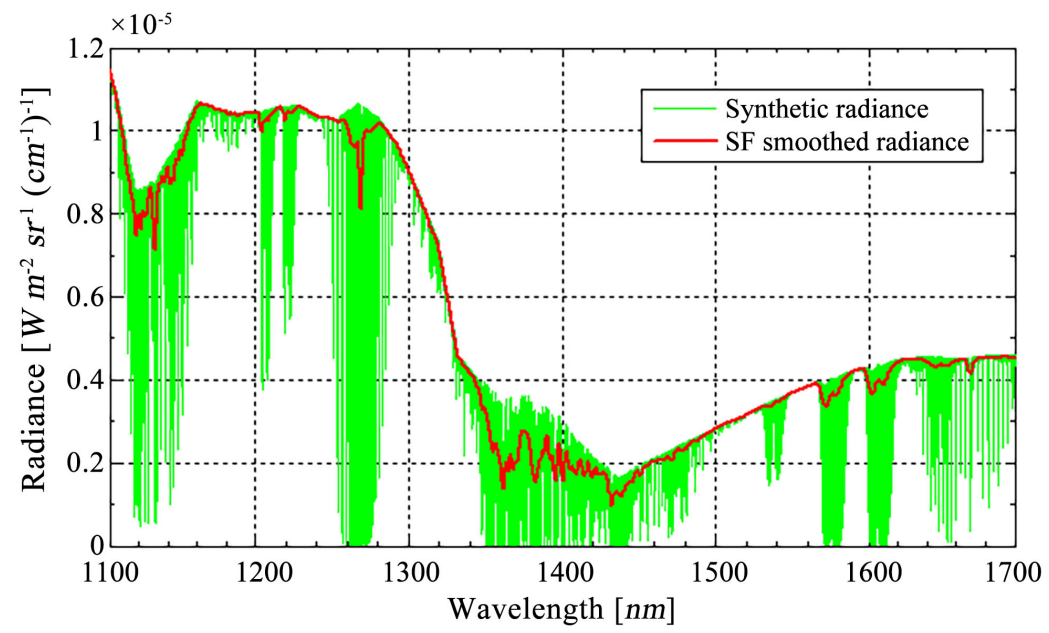

Figure 9. Synthetic radiance (smoothed) computed for cumulative wavelength dependent reflectance at $\mathrm{CF}=0.3$. 


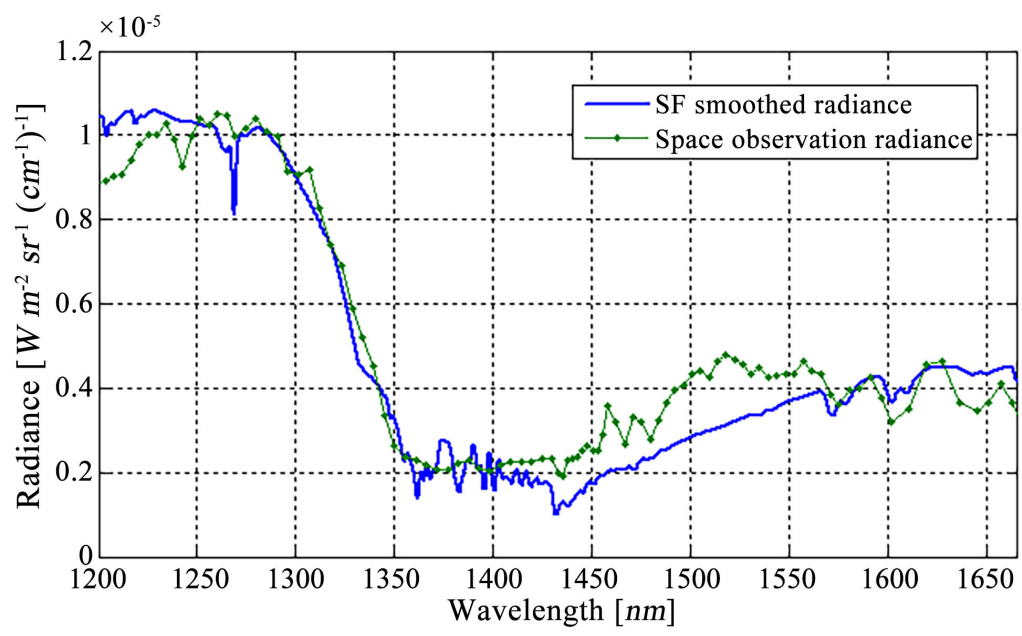

Figure 10. Comparison of synthetic radiance (smoothed) radiance and space observation radiance.

for carbon dioxide. The aerosol cloud due to forest fire and canopies makes a significant contribution in suppression of the radiance above $1400 \mathrm{~nm}$. The concentration of $\mathrm{CO}_{2}$ in calculation is increased by $40 \%$. Alongside with the $\mathrm{RE}$ model, the increased level of $\mathrm{CO}_{2}$ also supports an assumption for presence of the forest fire. The synthetic spectrum shown in Figure 10 has been computed by incorporating all four different types of surface reflectance, specifically due to aerosol cloud, pine trees, vegetation (broadleaf trees and bushes) and grass. Space observation radiance spectrum in Figure 10 corresponds to Argus week 11, pass 69, observation number 49 .

Figure 11(a) and Figure 11(b) show the absolute difference between synthetic and space observation data in $2 \mathrm{D}$ and $3 \mathrm{D}$ plots, respectively. As we can see from these figures, the darkest blue areas correspond to $\mathrm{CF}=0.3$. Change of vegetation CF higher than 0.6 or lower than 0.2 significantly increases the absolute difference. The weightages for the cloud, pine trees, vegetation (broadleaf plants and bushes) and grass are found to be $0.4,0.3,0.2$ and 0.1 , respectively. This signifies that corresponding areal coverage observed from space due to cloud, pine trees, vegetation and grass are about $40 \%, 30 \%, 20 \%$ and $10 \%$. It should also be mentioned that as an alternative to the areal coverage, the weighted sum can also be performed by computing corresponding proportions from the upwelling radiative flux [16].

The error analysis for this RE method shows a reasonable agreement between synthetic and Argus space observation radiance to detect the forest fire location with given IR wavelength range.

The space observed flux generally gives enhanced radiance due to larger oblique view angles as compared with nadir view angles because of high clouds and aerosols clouds thickness. Atmospheric path length and Albedo are also major contributors for high radiance enhancement. The latitude angular dependence is also an important parameter in our calculations to find RE [17]. 

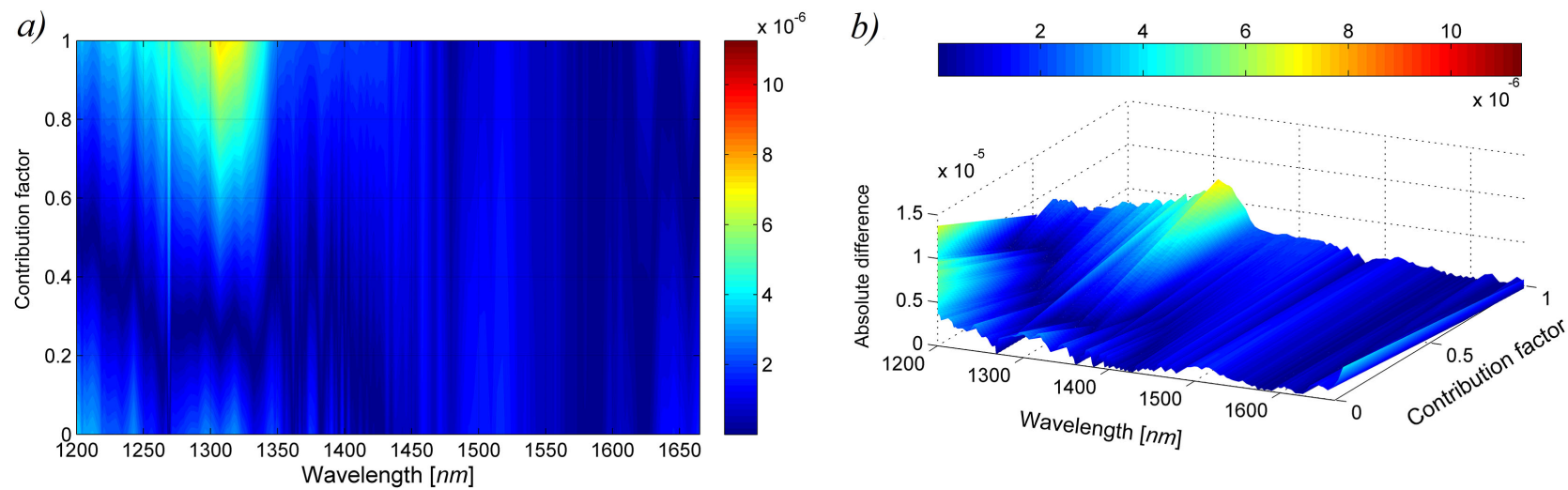

Figure 11. Absolute difference between synthetic and space observation data: (a) 2D plot and (b) 3D plot.

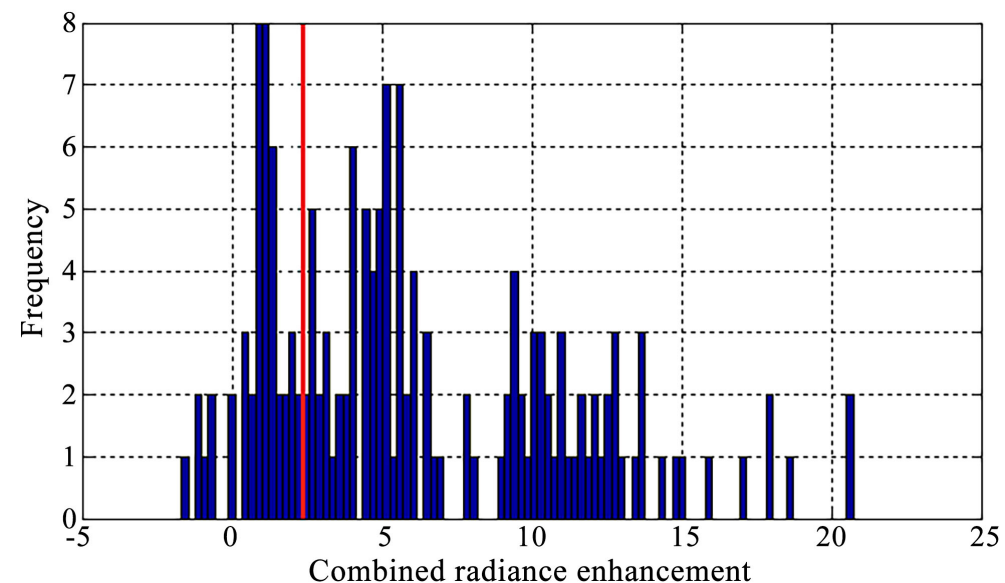

Figure 12. Frequency vs. CRE bar chart. The red line indicates the threshold value.

Table 1. RE and CRE values for the week 11, pass 69 and observation numbers 40 to 52 . $\mathrm{RE}_{1}, \mathrm{RE}_{2}, \mathrm{RE}_{3}$ and $\mathrm{RE}_{4}$ correspond to wavelength sub-bands of oxygen, water, Caron dioxide and methane gases, respectively.

\begin{tabular}{cccccccc}
\hline Week & Pass & Obs. \# & $\mathrm{RE}_{1}\left(\mathrm{O}_{2}\right)$ & $\mathrm{RE}_{2}\left(\mathrm{H}_{2} \mathrm{O}\right)$ & $\mathrm{RE}_{3}\left(\mathrm{CO}_{2}\right)$ & $\mathrm{RE}_{4}\left(\mathrm{CH}_{4}\right)$ & $\mathrm{CRE}$ \\
\hline 11 & 69 & 40 & 0.7214 & 2.3448 & 2.2607 & 0.7834 & 6.1102 \\
11 & 69 & 41 & 0.5492 & 1.7648 & 1.7273 & 0.5089 & 4.5502 \\
11 & 69 & 42 & -0.0069 & 0.7539 & 0.8769 & 0.0397 & 1.6636 \\
11 & 69 & 43 & 0.1352 & 0.4298 & 0.615 & 0.0722 & 1.2522 \\
11 & 69 & 44 & 0.1246 & 0.2132 & 0.2155 & -0.1365 & 0.4167 \\
11 & 69 & 45 & -0.4142 & -0.1229 & -0.067 & -0.4073 & -1.0113 \\
11 & 69 & 46 & -0.3924 & -0.113 & -0.0667 & -0.4059 & -0.9780 \\
11 & 69 & 47 & -0.314 & -0.0415 & 0.0303 & -0.3355 & -0.6607 \\
11 & 69 & 48 & -0.0751 & 0.1653 & 0.4447 & 0.0136 & 0.5485 \\
11 & 69 & 49 & -0.7862 & -0.3051 & -0.1234 & -0.4657 & -1.6803 \\
11 & 69 & 50 & -0.4827 & -0.1165 & -0.048 & -0.4106 & -1.0578 \\
11 & 69 & 51 & 0.4464 & 0.8823 & 0.5352 & -0.0694 & 1.7946 \\
11 & 69 & 52 & 0.7483 & 1.2298 & 0.8868 & 0.2129 & 3.0778 \\
\hline
\end{tabular}


Table 1 shows the RE and CRE values of individual wavelength bands of $\mathrm{O}_{2}$, $\mathrm{H}_{2} \mathrm{O}, \mathrm{CO}_{2}$ and $\mathrm{CH}_{4}$. The lower values in $\mathrm{RE}$ and CRE correspond to thick clouds or forest fire aerosol clouds, that occur due to high reflectance. In this study we used selected bunch of space observed values from observation numbers 40 to 52. The observation numbers 43 to 49 are in a good agreement with our RE model for the forest fire detection.

In our RE model we incorporate all important parameters as discussed in this section. Figure 12 demonstrates the frequency bar chart of aerosol cloud scene due to forest fire (both parameters are unitless). The vertical red line separates forest fire cloud scene reflectance (due to CRE) with higher reflectance due to other surfaces. Future work requires elaboration and analysis of the CRE values within range on the right side from the red line in order to clarify the nature of the relatively high reflectance.

In the development of this approach we applied the weighted sum based on a real coverage with different canopy constituents. The determination of areal coverage by canopies can be found, for example, by fractional calculus and retinex [45] that can be used to improve texture information of an image, similar to one shown in Figure 5.

As a future development we work on RE methods and algorithms that can be used to distinguish water vapor/ice clouds from forest or wildfire clouds without weather forecast and image processing datasets. This can be achieved, for example, by matching not only Albedo but also enhanced column of $\mathrm{CO}_{2}$ greenhouse gas concentration due to intense forest or field fires.

\section{Conclusion}

In this work we generalize the Radiance Enhancement method for detection of the cloud scenes to detection of the forest fires. This method can cover a wide spectral range from $1100 \mathrm{~nm}$ to $1700 \mathrm{~nm}$ by using space observation datasets of Argus 1000 micro-spectrometer. The RE method can be implemented for detection of combustion aerosols due to high sunlight reflectance of the smoke originated from the forest fires. Our model accounts for the wavelength dependent reflectance and is developed by a new method based on the weighted sum. As the nanosatellite rotates periodically around the Earth, the proposed approach may be a promising technique for continuous monitor of dynamics of the seasonal forest fires.

\section{Acknowledgements}

This study is supported by Department of Physics and Astronomy at York University, Epic College of Technology, Epic Climate Green (ECG) Inc. and Thoth Technologies Inc. The authors would like to express their gratitude to Dr. Robert Zee and his team from University of Toronto Institute for Aerospace Studies for support, guidance and suggestions in operating of the CanX-2 spacecraft. 


\section{Conflicts of Interest}

The authors declare no conflicts of interest regarding the publication of this paper.

\section{References}

[1] Apadula, F., Cassardo, C., Ferrarese, S., Heltai, D. and Lanza, A. (2019) Thirty Years of Atmospheric $\mathrm{CO}_{2}$ Observations at the Plateau Rosa Station, Italy. Atmosphere, 10, 418. https://dx.doi.org/10.3390/atmos10070418

[2] Karnauskas, K.B., Miller, S.L. and Schapiro, A.C. (2020) Fossil Fuel Combustion Is Driving Indoor $\mathrm{CO}_{2}$ toward Levels Harmful to Human Cognition. GeoHealth, 4, e2019GH000237. https://doi.org/10.1029/2019GH000237

[3] Ueyama, M., Ichii, K., Kobayashi, H., Kumagai, T., Beringer, J., Merbold, L., Euskirchen, E.S., Hirano, T., Marchesini, L.B., Baldocchi, D., Saitoh, T.M., Mizoguchi, Y., Ono, K., Kim, J., Varlagin, A., Kang, M., Shimizu, T., Kosugi, Y., Bret-Harte, M.S., Machimura, T., Matsuura, Y., Ohta, T., Takagi, K., Takanashi, S. and Yasuda, Y. (2020) Inferring $\mathrm{CO}_{2}$ Fertilization Effect Based on Global Monitoring Land-Atmosphere Exchange with a Theoretical Model. Environmental Research Letters, 15, Article ID: 084009. https://doi.org/10.1088/1748-9326/ab79e5

[4] Scarpa, G., Berrang-Ford. L., Zavaleta-Cortijo, C., Marshall, L., Harper, S.L. and Cade, J.E. (2020) The Effect of Climatic Factors on Nutrients in Foods: Evidence from a Systematic Map. Environmental Research Letters, 15, Article ID: 113002. https://doi.org/10.1088/1748-9326/abafd4

[5] Guo, F., Shen, X., Zou, L., Ren, Y., Qin, Y., Wang, X. and Wu, J. (2015) Cloud Detection Method Based on Spectral Area Ratios in MODIS Data. Canadian Journal of Remote Sensing, 41, 561-576. https://doi.org/10.1080/07038992.2015.1112729

[6] Fournier, N., Stammes, P., Graaf, M.D., Piters. A., Grzegorski, M. and Kokhanovsky, A. (2006) Improving Cloud Information over Deserts from SCIAMACHY Oxygen A-Band Measurements. Atmospheric Chemistry and Physics, 6, 163-172. https://doi.org/10.5194/acp-6-163-2006

[7] Mitchell, D.L. and Finnegan, W. (2009) Modification of Cirrus Clouds to Reduce Global Warming. Environmental Research Letters, 4, Article ID: 045102. https://doi.org/10.1088/1748-9326/4/4/045102

[8] Siddiqui, R., Jagpal, R., Salem, N.A. and Quine, B.M. (2015) Classification of Cloud Scenes by Argus Spectral Data. International Journal of Space Science and Engineering, 3, 295-311. https://doi.org/10.1504/IJSPACESE.2015.075911

[9] Tymstra, C., Stocks, B.J., Cai. X. and Flannigan, M.D. (2020) Wildfire Management in Canada: Review, Challenges and Opportunities. Progress in Disaster Science, 5, Article ID: 100045. https://doi.org/10.1016/j.pdisas.2019.100045

[10] Ganteaume, A., Camia, A., Jappiot, M., San-Miguel-Ayanz, J., Long-Fournel, M. and Lampin, C. (2013) A Review of the Main Driving Factors of Forest Fire Ignition over Europe. Environmental Management, 51, 651-662. https://doi.org/10.1007/s00267-012-9961-z

[11] Axelson, J.N., Alfaro, R.I. and Hawkes, B.C. (2009) Influence of Fire and Mountain Pine Beetle on the Dynamics of Lodgepole Pine Stands in British Columbia, Canada. Forest Ecology and Management, 257, 1874-1882. https://doi.org/10.1016/j.foreco.2009.01.047

[12] Parisien. M.A., Barber, Q.E., Hirsch, K.G., Stockdale, C.A., Erni, S., Wang, X., Arseneault, D. and Parks, S.A. (2020) Fire Deficit Increases Wildfire Risk for Many 
Communities in the Canadian Boreal Forest. Nature Communications, 11, Article No. 2121. https://doi.org/10.1038/s41467-020-15961-y

[13] Holm, S.M., Miller, M.D. and Balmes, J.R. (2021) Health Effects of Wildfire Smoke in Children and Public Health Tools: A Narrative Review. Journal of Exposure Science \& Environmental Epidemiology, 31, 1-20. https://doi.org/10.1038/s41370-020-00267-4

[14] Wind, G., Platnick, S., King, M.D., Hubanks, P.A., Pavolonis, M.J., Heidinger, A.K., Yang, P. and Baum, B.A. (2010) Multilayer Cloud Detection with the MODIS NearInfrared Water Vapor Absorption Band. Journal of Applied Meteorology and Climatology, 49, 2315-2333. https://doi.org/10.1175/2010JAMC2364.1

[15] Tang, H., Yu, K., Hagolle, O., Jiang, K., Geng, X. and Zhao, Y. (2013) A Cloud Detection Method Based on a Time Series of MODIS Surface Reflectance Images. International Journal of Digital Earth, 6, 157-171. https://doi.org/10.1080/17538947.2013.833313

[16] Siddiqui, R., Jagpal. R. and Quine, B.M. (2017) Short Wave Upwelling Radiative Flux (SWupRF) within Near Infrared (NIR) Wavelength Bands of $\mathrm{O}_{2}, \mathrm{H}_{2} \mathrm{O}, \mathrm{CO}_{2}$ and $\mathrm{CH}_{4}$ by Argus 1000 along with GENSPECT Line by Line Radiative Transfer Model. Canadian Journal of Remote Sensing, 43, 330-344. https://doi.org/10.1080/07038992.2017.1346467

[17] Siddiqui, R. (2017) Efficient Detection of Cloud Scenes by a space orbiting Argus 1000 Micro-Spectrometer. Ph.D. Thesis, York University, Toronto.

[18] Siddiqui, R., Jagpal, R.K., Abrarov, S.M. and Quine, B.M. (2020) Radiance Enhancement and Shortwave Upwelling Radiative Flux Methods for Efficient Detection of Cloud Scenes. International Journal of Space Science and Engineering, 6, 1-27. https://doi.org/10.1504/IJSPACESE.2020.109745

[19] Rankin, D., Kekez, D.D., Zee, R.E., Pranajaya, F.M., Foisy, D.G. and Beattie, A.M. (2005) The CanX-2 Nanosatellite: Expanding the Science Abilities of Nanosatellites. Acta Astronautica, 57, 167-174. https://doi.org/10.1016/j.actaastro.2005.03.032

[20] Jagpal, R.K. (2011) Calibration and Validation of Argus 1000 Spectrometer-A Canadian Pollution Monitor. Ph.D. Thesis, York University, Toronto.

[21] Jagpal, R.K., Quine, B.M., Chesser, H., Abrarov, S. and Lee, R. (2010) Calibration and in-Orbit Performance of the Argus 1000 Spectrometer-The Canadian Pollution Monitor. Journal of Applied Remote Sensing, 4, Article ID: 049501. https://doi.org/10.1117/1.3302405

[22] Jagpal, R.K., Siddiqui, R., Abrarov, S.M. and Quine, B.M. (2019) Carbon Dioxide Retrieval of Argus 1000 Space Data by Using GENSPECT Line-by-Line Radiative Transfer Model. Environment and Natural Resources Research, 9, 77-85.

[23] Siddiqui, R., Jagpal, R.K., Abrarov, S.M. and Quine, B.M. (2020) A New Approach to Detect Combustion-Originated Aerosols by Using a Cloud Method. AGU Fall Meeting Abstracts, 2020, A211-0004.

[24] Natural Resources Canada. https://www.nrcan.gc.ca/home

[25] Alkhatib, A.A.A. (2014) A Review on Forest Fire Detection Techniques. International Journal of Distributed Sensor Networks, 10, Article ID: 597368. https://doi.org/10.1155/2014/597368

[26] Wang, S.D., Miao, L.L. and Peng, G.X. (2013) An Improved Algorithm for Forest Fire Detection Using HJ Data. Procedia Environmental Sciences, 13, 140-150. https://doi.org/10.1016/j.proenv.2012.01.014

[27] Benali, A., Russo, A., Sá, A.C.L., Pinto, R.M.S., Price, O., Koutsias, N. and Pereira, 
J.M.C. (2016) Determining Fire Dates and Locating Ignition Points with Satellite Data. Remote Sensing, 8, 326. https://doi.org/10.3390/rs8040326

[28] Quine, B.M. and Drummond, J.R. (2002) GENSPECT: A Line-by-Line Code with Selectable Interpolation Error Tolerance. Journal of Quantitative Spectroscopy and Radiative Transfer, 74, 147-165. https://doi.org/10.1016/S0022-4073(01)00193-5

[29] Hill, C., Gordon, I.E., Kochanov, R.V., Barrett. L., Wilzewski, J.S. and Rothman, L.S. (2016) HITRANonline: An Online Interface and the Flexible Representation of Spectroscopic Data in the HITRAN Database. Journal of Quantitative Spectroscopy and Radiative Transfer, 177, 4-14. https://doi.org/10.1016/j.jqsrt.2015.12.012

[30] Abrarov, S.M., Quine, B.M., Siddiqui, R. and Jagpal, R.K. (2019) A Single-Domain Implementation of the Voigt/Complex Error Function by Vectorized Interpolation. Earth Sciences Research Journal, 8, 52-63.

[31] Abrarov, S.M. and Quine, B.M. (2011) Efficient Algorithmic Implementation of the Voigt/Complex Error Function Based on Exponential Series Approximation. Applied Mathematics and Computation, 218, 1894-1902. https://doi.org/10.1016/j.amc.2011.06.072

[32] Abrarov, S.M., Quine, B.M. and Jagpal, R.K. (2018) A Sampling-Based Approximation of the Complex Error Function and Its Implementation without Poles. Applied Numerical Mathematics, 129, 181-191. https://doi.org/10.1016/j.apnum.2018.03.009

[33] Abrarov, S.M. and Quine, B.M. (2018) A Rational Approximation of the Dawson's Integral for Efficient Computation of the Complex Error Function. Applied Mathematics and Computation, 321, 526-543.

https://doi.org/10.1016/j.amc.2017.10.032

[34] Fomin, B.A. (1995) Effective Interpolation Technique for Line-by-Line Calculations of Radiation Absorption in Gases. Journal of Quantitative Spectroscopy and Radiative Transfer, 53, 663-669. https://doi.org/10.1016/0022-4073(95)00029-K

[35] Sparks, L. (1997) Efficient Line-by-Line Calculation of Absorption Coefficients to High Numerical Accuracy. Journal of Quantitative Spectroscopy and Radiative Transfer, 57, 631-650. https://doi.org/10.1016/S0022-4073(96)00154-9

[36] Roberts, Y.L., Pilewskie, P., Kindel, B.C., Feldman, D.R. and Collins, W.D. (2013) Quantitative Comparison of the Variability in Observed and Simulated Shortwave Reflectance. Atmospheric Chemistry and Physics, 13, 3133-3147. https://doi.org/10.5194/acp-13-3133-2013

[37] Li, S., Suna, D., Goldberg, M.D., Sjoberg, B., Santek, D., Hoffman, J.P., DeWeese, M., Restrepo, P., Lindsey. S. and Holloway, E. (2018) Automatic Near Real-Time Flood Detection Using Suomi-NPP/VIIRS Data. Remote Sensing of Environment, 204, 672 689. https://doi.org/10.1016/j.rse.2017.09.032

[38] MODIS Land. https://modis-land.gsfc.nasa.gov/

[39] Baldridge, A.M., Hook, S.J., Grove, C.I. and Rivera, G. (2009) The ASTER Spectral Library Version 2.0. Remote Sensing of Environment, 113, 711-715.

https://doi.org/10.1016/j.rse.2008.11.007

[40] Gupta, P., Christopher, S.A., Wang, J., Gehrig, R., Lee, Y. and Kumar, N. (2006) Satellite Remote Sensing of Particulate Matter Air Quality: The Cloud-Cover Problem. Atmospheric Environment, 40, 5880-5892. https://doi.org/10.1016/j.atmosenv.2006.03.016

[41] Mamun, A., Chen, Y. and Liang, J. (2021) Radiative and Cloud Microphysical Effects of the Saharan Dust Simulated by the WRF-Chem Model. Journal of Atmospheric and Solar-Terrestrial Physics, 219, Article ID:105646. https://doi.org/10.1016/j.jastp.2021.105646 
[42] Systems Tool Kit (STK). https://www.agi.com/products/stk

[43] Google Earth. https://www.google.com/earth/

[44] EOSDIS Worldview. https://worldview.earthdata.nasa.gov/

[45] Cao, J. (2018) An Image Enhancement Method Based on Fractional Calculus and Retinex. Journal of Computer and Communications, 6, 55-65.

https://doi.org/10.4236/jcc.2018.611005 